\title{
Laihunite in planetary materials: An FTIR and TEM study of oxidized synthetic and meteoritic Fe-rich olivine
}

\author{
Naotaka ToMIOKA ${ }^{*, * *}$, Andreas MorLOK ${ }^{*, * * *,}$, Chiyoe KoIKE ${ }^{\dagger, *}$, \\ Melanie KÖHLER ${ }^{\#}$ and Monica GRADY ${ }^{* * *, \S}$ \\ *Department of Earth and Planetary Sciences, Graduate School of Science, Kobe University, Kobe 657-8501, Japan \\ ${ }^{* *}$ Institute for Study of the Earth's Interior, Okayama University, Misasa, Tottori 682-0193, Japan \\ ${ }^{* * *}$ Department of Mineralogy, The Natural History Museum, Cromwell Road, London SW7 5BD, UK \\ ${ }^{\dagger}$ Department of Physics, Kyoto Pharmaceutical University, Kyoto 607-8414, Japan \\ ${ }^{\ddagger}$ Department of Earth and Space Science, Graduate School of Science, \\ Osaka University, Toyonaka 560-0043, Japan \\ \#Institut d'Astrophysique Spatiale, Universite Paris Sud, 91405, Orsay, France \\ ${ }^{\S}$ DPS, The Open University, Walton Hall, Milton Keynes MK7 6AA, UK
}

\begin{abstract}
In situ mid-infrared transmission measurements of matrices from carbonaceous chondrites heated up to $572{ }^{\circ} \mathrm{C}$ in air were conducted by FTIR spectroscopy. The FTIR spectra of the matrices mainly showed olivine bands. With increasing temperature, up to $477{ }^{\circ} \mathrm{C}$, the spectra did not show significant changes. However, at $572{ }^{\circ} \mathrm{C}$, the $\sim 11-\mu \mathrm{m}$ band split into a doublet, and the intensity of the $\sim 10-\mu \mathrm{m}$ band relative to that of the $\sim 11-\mu \mathrm{m}$ band increased significantly. In synthetic Fe-rich olivine $\left(\mathrm{Fo}_{47}\right)$ samples heated at $600{ }^{\circ} \mathrm{C}$ in air, their mid-infrared spectra showed changes similar to those in meteoritic samples. A TEM observation of the recovered meteoritic samples showed that most olivine grains had a stacking disorder on (001). Selected area electron diffraction patterns of the grains also exhibited extra reflections, corresponding to a similar superstructure to three-fold periodicity along $c_{\mathrm{ol}}$ known as laihunite- $3 \mathrm{M}$ in $\mathrm{Fe}_{2} \mathrm{SiO}_{4}$. Although the synthetic Fe-rich olivine did not have any defect structures before heating, the olivine commonly had a stacking disorder on (001) after heating at $600{ }^{\circ} \mathrm{C}$. Therefore, the changes in mid-infrared spectra of the matrices of carbonaceous chondrites were not caused by chemical reactions among their constituent minerals, but were mainly caused by oxidation of iron within the olivine structure. The mid-infrared spectra of olivine-dominating samples from this study are potential reference data for the oxidation state of olivine in in situ mid-infrared measurements on the Martian surface, in partially oxidized meteorites, on asteroidal surfaces, and in interplanetary dust particles.
\end{abstract}

Keywords: Fe-rich olivine, Laihunite, Carbonaceous chondrites, Infrared spectroscopy, Transmission electron microscopy

\section{INTRODUCTION}

The oxidation state of iron in planetary materials such as meteorites and dust particles is the key to understanding $f_{\mathrm{O}_{2}}$ conditions and water activities that these planetary materials have experienced. Among silicates in planetary materials, olivine is one of the major hosts of iron. At high $f_{\mathrm{O}_{2}}$ conditions, iron-bearing olivine transforms to ferric iron-bearing phases such as magnetite, hematite, and a superstructure of olivine known as laihunite (e.g., Shen et al., 1986; Tamada et al., 1983). Laihunite forms in a variety of terrestrial processes such as metasomatism of mandoi:10.2465/jmps.120409

N.Tomioka, nao@misasa.okayama-u.ac.jp Corresponding author tle olivine (Banfield et al., 1992). Moreover, meteoritic and planetary materials may also be exposed to oxidizing environments during aqueous alteration or metasomatism on their parent bodies (Brearley, 2003; Tomeoka and Buseck, 1990). Hence, knowledge of the effects of oxidation on the dominating Fe-bearing minerals is crucial; it allows the determination of the formation environment. Since olivine is a very common phase in meteoritic and planetary materials, oxidation-related changes to this mineral are of high interest.

Recent findings have shown that the environment on Mars was much more "wet" and oxidizing in the past (Ehlman et al. 2011; Wiseman et al. 2010). As a secondary phase in Martian meteorites, laihunite proved to be a 
useful marker to estimate the formation environment. Micro-Raman spectroscopy, scanning electron microscopy, transmission electron microscopy (TEM), and X-ray diffraction studies of crack- and vein-fillings in nakhlites suggested fluid-assisted alteration in the $400{ }^{\circ} \mathrm{C}$ to $800^{\circ} \mathrm{C}$ range (Noguchi et al., 2009; Rost et al., 2006). This laihunite-like phase was also rich in $\mathrm{Li}$, which is a fluid-mobile element, and the phase was regarded to be a reaction product of fayalite with water in nakhlite magma (Rost et al., 2006). TEM, micro-Raman, Mössbauer, electron spin resonance, and optical spectroscopic studies on browncolored olivine in shergottites and chassignites suggested that the ferric iron was produced by oxidation during heavy shock metamorphism on the Martian surface (Bläß et al., 2010; Ostertag et al., 1984). In addition, laihunite was considered to be a potential phase occurring on the surface of Venus (Fegley et al., 1992).

Laihunite also occurs as a sensitive marker for the oxidation environment of interplanetary dust particles (IDPs). The mineral was found in chondritic-porous IDPs (Keller et al., 1992, 1996; Rietmeijer, 1993). In this case, laihunite probably formed as a result of the heat pulse during atmospheric entry of the IDPs (Greshake et al., 1994; Guofei and Rietmeijer, 1994; Keller at al., 1992). However, laihunite also formed in laboratory studies of annealed vapor condensates while investigating dust formation in protoplanetary environments (Guofei and Rietmeijer, 1994). In more recent experiments (Nozaki et al., 2006) to simulate heating of micrometeorites during atmospheric re-entry, laihunite formed in samples of the Orgueil CI chondrite at $\sim 900^{\circ} \mathrm{C}$ and 0.8 torr.

In this study, which is part of a project to investigate environmental effects on the mid-infrared spectral properties of planetary materials, we report the oxidation of $\mathrm{Fe}$ in synthetic and meteoritic olivines to laihunite, based on Fourier transform infrared spectroscopy (FTIR) and TEM. In FTIR measurements, direct structural information from both crystalline and amorphous materials can be obtained from a few samples. In addition, FTIR is a non-destructive measurement and has better sensitivity for minor components than Raman spectroscopy. Therefore, it is useful not only to analyze the oxidation state of meteorites but also for in situ measurements of rocks by future Mars landers and rovers (Anderson et al., 2005).

Thus far, laihunite has been mainly investigated with terrestrial applications in mind. However, mid-infrared analyses of laihunite are very rare and have either focused on the study of water content (Banfield et al., 1992) or been of very low resolution (Huggins, 1970; Schaefer, 1985; Zhang et al., 1981). In the present study, we aimed to inspect this sensitive marker for redox states of mineral assemblages in the context of their occurrences in plane- tary and meteoritic environments.

\section{EXPERIMENTAL METHODS}

The matrices of the carbonaceous chondrites used in this study were from samples obtained from the collection of the Natural History Museum in London: Vigarano (CV) (catalogue number: BM1911, 174), Ningqiang (CV) (BM2000, M1), and Ornans (CO) (BM1985, M149). CV and $\mathrm{CO}$ matrices consist mainly of olivine and lesser amounts of pyroxene, $\mathrm{Fe}$-metal, $\mathrm{Fe}$-sulfide, and $\mathrm{Fe}$-oxide (Buseck and Hua, 1993). Matrix olivines in the samples are rich in $\mathrm{Fe}$ with $\mathrm{Fo}_{47-85}$ (Vigarano: Lee et al., 1996), $\mathrm{Fo}_{26-65}$ (Ningqiang: Zolensky et al., 2003), $\mathrm{Fo}_{40-52}$ (Ornans: Brearley and Jones, 1998) compositions. The materials were crushed to a very fine powder $(<1 \mu \mathrm{m})$ using a diamond compression cell and placed on infrared transparent $\mathrm{KBr}$ pellets using a tungsten needle. In situ mid-infrared transmission/absorption spectra $(2.5 \mu \mathrm{m}$ to $25.0 \mu \mathrm{m})$ of the samples at temperatures up to $572{ }^{\circ} \mathrm{C}$ were taken using a Perkin Elmer AutoIMAGE FT-IR microscope at the Natural History Museum, equipped with a calibrated heating stage (Linkam FTIR), using a spectral resolution of 4 $\mathrm{cm}^{-1}$. Fifty scans were completed for each measurement. The heating path consisted of $\sim 100{ }^{\circ} \mathrm{C}$ steps $\left(5^{\circ} \mathrm{C} / \mathrm{min}\right)$, with a 5 min equilibration time before each infrared measurement. After cooling, the samples were analyzed by the same method with synthetic olivine as described below.

To compare the results of meteoritic samples, synthetic $\mathrm{Fe}$-rich olivine $\left(\mathrm{FO}_{47}\right)$ was also investigated by FTIR. The olivine was crushed using agate mortar and directly put on a $\mathrm{Pt}$ foil and a $\mathrm{KBr}$ pellet. Respective samples were heated up to $600{ }^{\circ} \mathrm{C}$ in $1 \mathrm{~h}$ and kept at the temperature for $0.5 \mathrm{~h}$ in air in an electric furnace, and then cooled to room temperature in $1 \mathrm{~h}$. These synthetic olivines were analyzed by an FTIR spectrometer before and after heating. An FTIR spectrum of the Fe-rich olivine was obtained using the $\mathrm{KBr}$-pellet technique. Here, a submicron powder of sample was ground well with $\mathrm{KBr}$, of which $200 \mathrm{mg}$ was pressed into a pellet. Analyses were carried out using a Nicolet Nexus 670 FTIR workbench at the Kyoto Pharmaceutical University, with 512 scans completed. Spectral resolution in all cases was $4 \mathrm{~cm}^{-1}$. The results of absorbance $\left[A=\log _{10}(100 / T)\right]$ were corrected using a baseline joining of the low-points in the spectra between 7 and $16 \mu \mathrm{m}$. Following this, spectra were normalized to the weakest and strongest silicate bands. Further details of the sample preparation and measurements of FTIR are described in Morlok et al. (2006).

Mineral aggregates of cooled Vigarano and Ningqiang samples were removed from the $\mathrm{KBr}$ pellets by a 
tungsten needle and were embedded in epoxy. They were processed to thin foils of 70-75 nm thickness using an ultramicrotome. Synthetic Fe-rich olivine powder before and after heating on a platinum foil was directly mounted on $\mathrm{Cu}$ grids, which were covered with a formvar/carbon film. All samples were examined using a transmission electron microscope (JEOL JEM-2010) at the Kobe University, operated at an accelerating voltage of $200 \mathrm{kV}$. The crystal structure was identified by selected area electron diffraction (SAED) and high-resolution imaging.

\section{RESULTS}

\section{FTIR measurements}

In the FTIR spectra of the matrix of the Vigarano chondrite, strong absorption bands were observed at $\sim 10 \mu \mathrm{m}$, $\sim 11 \mu \mathrm{m}$, and $\sim 12 \mu \mathrm{m}$ (Table 1 and Fig. 1). The $10-11 \mu \mathrm{m}$ and $12 \mu \mathrm{m}$ bands were attributed to asymmetric $\left(v_{3}\right)$ and symmetric $\left(v_{1}\right) \mathrm{Si}-\mathrm{O}$ stretching vibrations within the $\mathrm{SiO}_{4}$ tetrahedra of the olivine structure, respectively (Hofmeister, 1987). The $11-\mu \mathrm{m}$ band was the strongest, and the $10^{-}$ $\mu \mathrm{m}$ one was the second strongest among the three bands. At temperatures up to $286^{\circ} \mathrm{C}$, no significant change was observed. Above $382^{\circ} \mathrm{C}$, the intensity of the $10-\mu \mathrm{m}$ band conspicuously increased, and became the strongest band at $572{ }^{\circ} \mathrm{C}$. Another major spectral change observed was the splitting of the 11- $\mu \mathrm{m}$ band into a double band (Table 1 and Fig. 1). After cooling to room temperature, the splitting of the $11-\mu \mathrm{m}$ band into separate bands at $11.2 \mu \mathrm{m}$ and $11.6 \mu \mathrm{m}$ became more obvious. Additionally, a band at $12.2 \mu \mathrm{m}$ and a shoulder at $\sim 9.8 \mu \mathrm{m}$ appeared.

The Ningqiang matrix showed similar changes in mid-infrared spectra to those of Vigarano, except the presence of a $\sim 9.3 \mu \mathrm{m}$ band of minor pyroxene (Chihara et al., 2002). At $572{ }^{\circ} \mathrm{C}$, the intensity inversion from the $10-\mu \mathrm{m}$ band to $11-\mu \mathrm{m}$ band was also observed, as was the split of the $11-\mu \mathrm{m}$ band. The splitting into bands at 11.2 $\mu \mathrm{m}$ and $11.6 \mu \mathrm{m}$ also remained after cooling (Table 1 and Fig. 2). In addition to the bands at $9.8 \mu \mathrm{m}$ and $12.2 \mu \mathrm{m}$, a band at $14.4 \mu \mathrm{m}$ clearly appeared in the cooled sample.

The Ornans matrix also showed similar changes in mid-infrared spectra to those of Vigarano and Ningqiang. No significant change was observed up to $382^{\circ} \mathrm{C}$. Above $477^{\circ} \mathrm{C}$, the intensity of the $10-\mu \mathrm{m}$ band relative to that of the $11-\mu \mathrm{m}$ band began to increase. Intensity inversion of the $10-\mu \mathrm{m}$ band to the $11-\mu \mathrm{m}$ one or the splitting of the $11-\mu \mathrm{m}$ band did not occur, even at $572{ }^{\circ} \mathrm{C}$ (Table 1 and Fig. 3). However, splitting into bands at $11.2 \mu \mathrm{m}$ and 11.6 $\mu \mathrm{m}$ was clearly observed after cooling. A $9.1-\mu \mathrm{m}$ band appeared in the spectrum while heated above $477^{\circ} \mathrm{C}$, and a shoulder at $\sim 9.8 \mu \mathrm{m}$ in the spectrum after cooling also appeared (Fig. 3).

FTIR spectra of the synthetic olivine $\left(\mathrm{Fo}_{47}\right)$ before heating showed strong olivine bands at $\sim 10 \mu \mathrm{m}, 11 \mu \mathrm{m}$, and $12 \mu \mathrm{m}$, as in the meteoritic samples (Fig. 4). In the spectra from the synthetic olivine sample on a $\mathrm{KBr}$ pellet obtained at room temperature after heating at $600{ }^{\circ} \mathrm{C}$ in air, the intensity of the $10-\mu \mathrm{m}$ band increased relative to that of the $11-\mu \mathrm{m}$ band, but no inversion was observed. In addition, the $11-\mu \mathrm{m}$ band split into two bands at $11.2 \mu \mathrm{m}$ and $11.5 \mu \mathrm{m}$ (Fig. 4). A further band appeared at $12.3 \mu \mathrm{m}$. FTIR spectra of olivine after heating at $600{ }^{\circ} \mathrm{C}$ on a platinum foil yielded more noise, but showed the same spectral bands as that of the heated olivine on a $\mathrm{KBr}$ pellet. Figure 5 shows a comparison of infrared spectra among synthetic olivine and the matrices of chondrites taken after cooling. The Vigarano and Ningqiang samples showed splitting of the $11-\mu \mathrm{m}$ band and a large increase in the intensity of the $10-\mu \mathrm{m}$ band relative to that of the $11-\mu \mathrm{m}$ one. On the contrary, the above spectral changes were observed to be less significant for the Ornans matrix and synthetic olivines.

\section{TEM observations}

Under TEM observation, microtomed Vigarano samples after cooling mainly consisted of Fe-rich olivine $(<1 \mu \mathrm{m}$ in size) and a lesser amount of Si-rich amorphous material. Selected area electron diffraction (SAED) patterns of olivine grains showed strong diffraction spots from the olivine structure. However, most of the olivine grains also had weaker extra reflections along $c^{*}{ }_{\text {ol }}$ (Fig. 6). These extra spots correspond to a superstructure of three-fold periodicity along the $c$ axis of olivine. High-resolution TEM images could not be taken owing to a difficulty in making enough thin olivine grains for this purpose.

Ningqiang samples after cooling consisted mainly of Fe-rich olivine, high-Ca pyroxene, and a lesser amount of Si-rich amorphous material and hematite. All mineral grains were smaller than $1 \mu \mathrm{m}$ in size. Most of the olivine grains showed superlattice reflections along the $c^{*}$ axis of olivine, similar to heated Vigarano samples (Figs. 7a and 7b). Minor amounts of grains had streaking diffraction along the olivine $c^{*}$ axis and extra reflections different from those of the superstructure of olivine. The extra reflections were from a magnetite structure. The SAED pattern clarified that olivine and magnetite exhibit the following crystallographic orientation: $(100)_{\mathrm{ol}} / /\{111\}_{\mathrm{mag}}$ and $(001)_{\mathrm{ol}} / /\{101\}_{\mathrm{mag}}$ (Figs. 7c and 7d). (100) $)_{\mathrm{ol}}$ and $\{111\}_{\mathrm{mag}}$ correspond to close-packed oxygen layers of olivine and magnetite. This topotaxial olivine-magnetite intergrowth was previously reported in experimentally heated olivine in the Murchison meteorite (Nozaki et al., 2006). 
Table 1. FTIR band positions in the heated and original samples

\begin{tabular}{|c|c|c|c|c|c|c|c|c|}
\hline $\mathrm{T}\left({ }^{\circ} \mathrm{C}\right)$ & 25 & 96 & 191 & 286 & 382 & 477 & 572 & 25 (Cooled) \\
\hline \multirow[t]{6}{*}{ Vigarano } & & & & & & & & $9.8(\mathrm{sh})$ \\
\hline & 10.12 & 10.12 & 10.12 & 10.12 & $10.1(\mathrm{br})$ & & & 10.25 \\
\hline & 10.42 & 10.46 & 10.46 & 10.46 & 10.46 & 10.50 & 10.46 & \\
\hline & $11.31^{*}$ & $11.31^{*}$ & $11.31^{*}$ & $11.31^{*}$ & $11.31^{*}$ & 10.82 & $11.26^{\circ}$ & 11.15 \\
\hline & & & & & & $11.31^{*}$ & $11.63^{*}$ & $11.55^{*}$ \\
\hline & 12.02 & 12.02 & 12.02 & 12.02 & $12.0(\mathrm{sh})$ & & 12.32 & $\begin{array}{l}12.23 \\
16.15 \\
19.49\end{array}$ \\
\hline \multirow[t]{6}{*}{ Ningqiang } & 9.33 & 9.33 & 9.33 & 9.3(sh) & 9.43 & 9.43 & $9.4(\mathrm{sh})$ & \\
\hline & & & & & & 9.9(sh) & 9.9(sh) & $9.8(\mathrm{sh})$ \\
\hline & 10.29 & 10.29 & 10.25 & $\begin{array}{l}10.25 \\
10.42\end{array}$ & $\begin{array}{l}10.20 \\
10.46\end{array}$ & $\begin{array}{l}10.20 \\
10.37\end{array}$ & 10.37. & 10.27 \\
\hline & $11.42^{*}$ & $11.42^{*}$ & $11.42^{*}$ & $11.42^{*}$ & $11.42^{*}$ & $11.47^{*}$ & 11.47 & $11.20^{*}$ \\
\hline & 12.02 & 12.02 & 12.02 & 12.02 & $12.0(\mathrm{sh})$ & & 11.63 & $11.57^{\circ}$ \\
\hline & 14.20 & 14.89 & 14.20 & 14.53 & 14.53 & 14.53 & 12.32 & $\begin{array}{l}12.20 \\
14.44 \\
16.20 \\
19.64 \\
21.25\end{array}$ \\
\hline \multirow[t]{6}{*}{ Ornans } & & & & & & $9.1(\mathrm{sh})$ & $9.1(\mathrm{sh})$ & \\
\hline & 10.12 & 10.12 & 10.12 & 10.12 & 10.12 & & & $\begin{array}{l}9.8(\mathrm{sn}) \\
10.39\end{array}$ \\
\hline & 10.42 & 10.42 & 10.42 & 10.42 & 10.42 & 10.50 & $10.68{ }^{*}$ & $1122^{*}$ \\
\hline & $11.31^{*}$ & $11.36^{*}$ & $11.36^{*}$ & $11.36^{*}$ & $11.36^{*}$ & $11.36^{*}$ & 11.30 & 11.22 \\
\hline & & & & & & & $11.6(\mathrm{sh})$ & $\begin{array}{l}11.55^{*} \\
11.98\end{array}$ \\
\hline & 12.02 & 12.02 & 12.08 & 12.08 & 12.08 & $12.1(\mathrm{sh})$ & & $\begin{array}{l}12.2(\mathrm{sh}) \\
16.36 \\
19.64\end{array}$ \\
\hline Synthetic & & & & & & & & $9.8(\mathrm{sh})$ \\
\hline \multirow[t]{7}{*}{$\mathrm{Fo}_{47}(\mathrm{KBr})$} & 10.41 & & & & & & & 10.39 \\
\hline & & & & & & & & 11.15 \\
\hline & $11.37^{*}$ & & & & & & & $11.22^{*}$ \\
\hline & & & & & & & & $11.47^{*}$ \\
\hline & 12.00 & & & & & & & 11.55 \\
\hline & 17.22 & & & & & & & 12.26 \\
\hline & 20.66 & & & & & & & $16.5(\mathrm{br})$ \\
\hline Synthetic & 10.41 & & & & & & & 10.39 \\
\hline \multirow[t]{7}{*}{$\mathrm{Fo}_{47}(\mathrm{Pt})$} & & & & & & & & 10.76 \\
\hline & & & & & & & & 11.12 \\
\hline & & & & & & & & $11.22^{*}$ \\
\hline & $11.37^{\circ}$ & & & & & & & $11.47^{*}$ \\
\hline & 12.00 & & & & & & & 11.60 \\
\hline & 17.22 & & & & & & & 12.29 \\
\hline & 20.66 & & & & & & & $16.5(\mathrm{br})$ \\
\hline
\end{tabular}

All values are in microns.

*, Split bands at $\sim 11 \mu \mathrm{m}$.

Notes: "sh" and "br" denote shoulders and broad bands with no clear peak, respectively.

The $\mathrm{Fo}_{47}$ olivine before and after heating at $600{ }^{\circ} \mathrm{C}$ on a platinum foil was also examined by TEM. In the unheated olivine sample, none of the grains showed stacking disorder (Fig. 8a). On the contrary, in the heated olivine sample, half of the olivine grains exhibited stacking disor- der on the (001) plane (Fig. 8b), and some of them showed superlattice reflection along the $c^{*}$ direction, as in olivine from the meteoritic samples (Fig. 8c). The diffraction spots of magnetite were not observed in this sample. In the high-resolution TEM image, only fringes with 1.8 


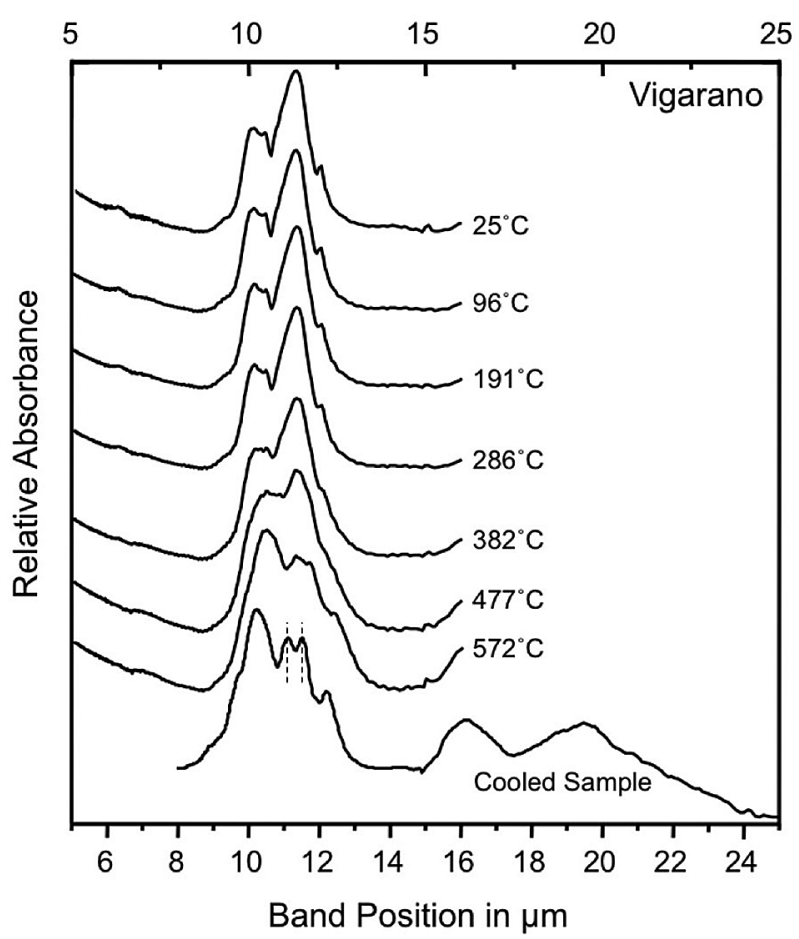

Figure 1. In situ mid-infrared spectra from $5 \mu \mathrm{m}$ to $25 \mu \mathrm{m}$ of the matrix of the Vigarano (CV) carbonaceous chondrite heated up to $572{ }^{\circ} \mathrm{C}$ and that after cooling. The band around $15 \mu \mathrm{m}$ comes from $\mathrm{CO}_{2}$ gas in air. Note that the $\sim 11-\mu \mathrm{m}$ band splits into a doublet in the spectrum after cooling (indicated by dotted lines).

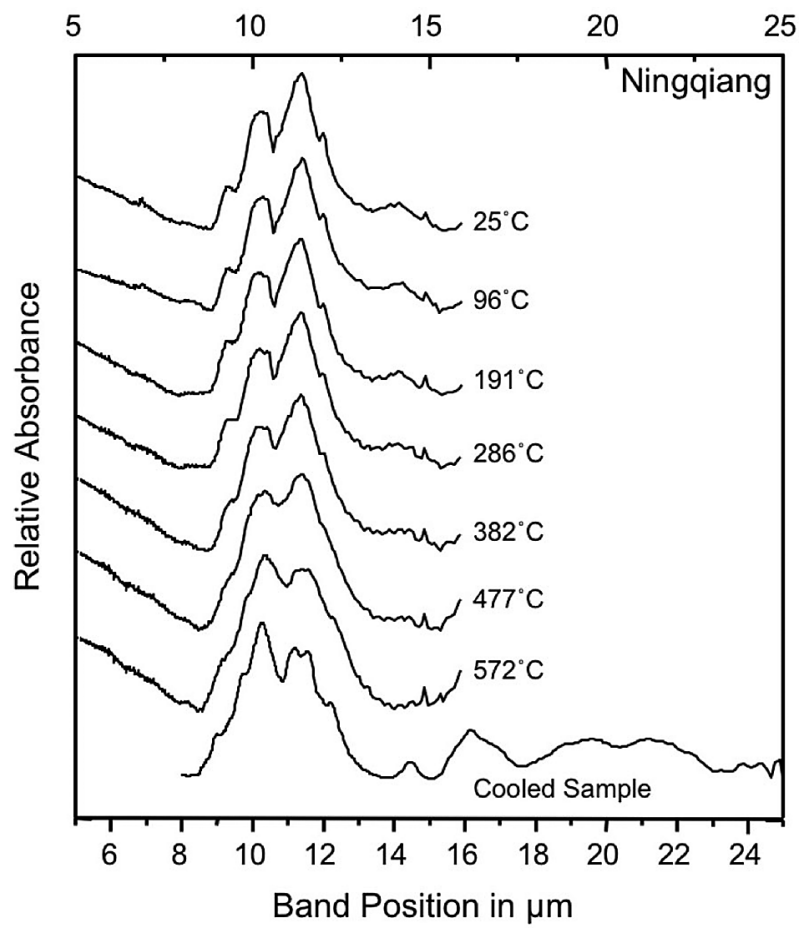

Figure 2. In situ mid-infrared spectra from $5 \mu \mathrm{m}$ to $25 \mu \mathrm{m}$ of the matrix of the Ningqiang $(\mathrm{CV})$ carbonaceous chondrite heated up to $572{ }^{\circ} \mathrm{C}$ and that after cooling.

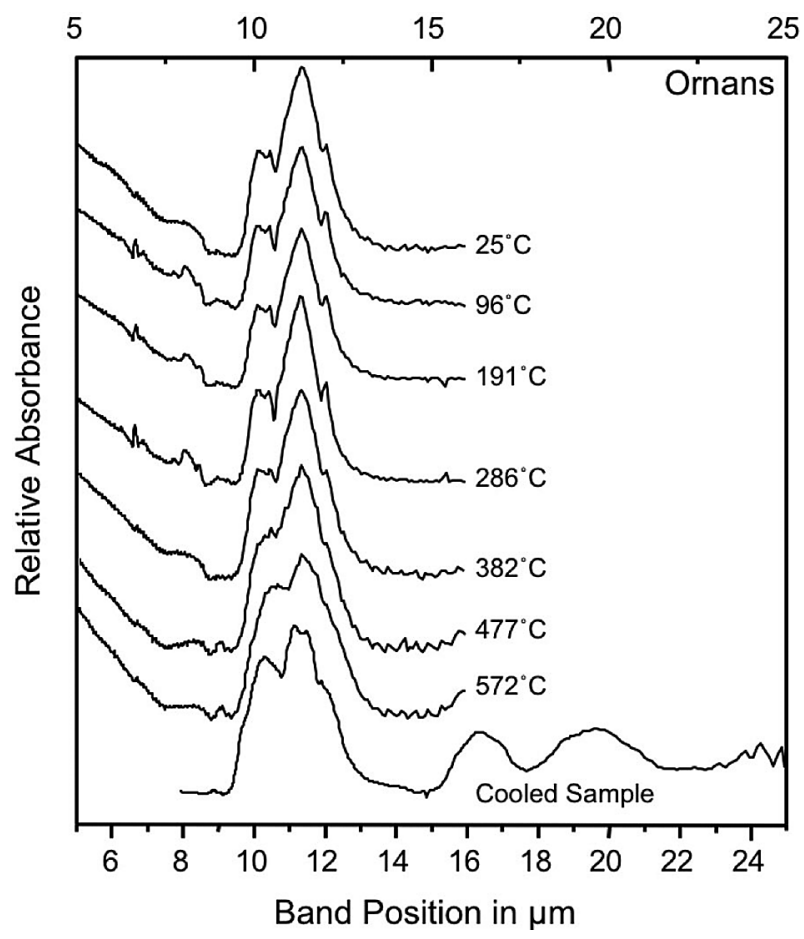

Figure 3. In situ mid-infrared spectra from $5 \mu \mathrm{m}$ to $25 \mu \mathrm{m}$ of the matrix of the Ornans (CO) carbonaceous chondrite heated up to $572{ }^{\circ} \mathrm{C}$ and that after cooling.

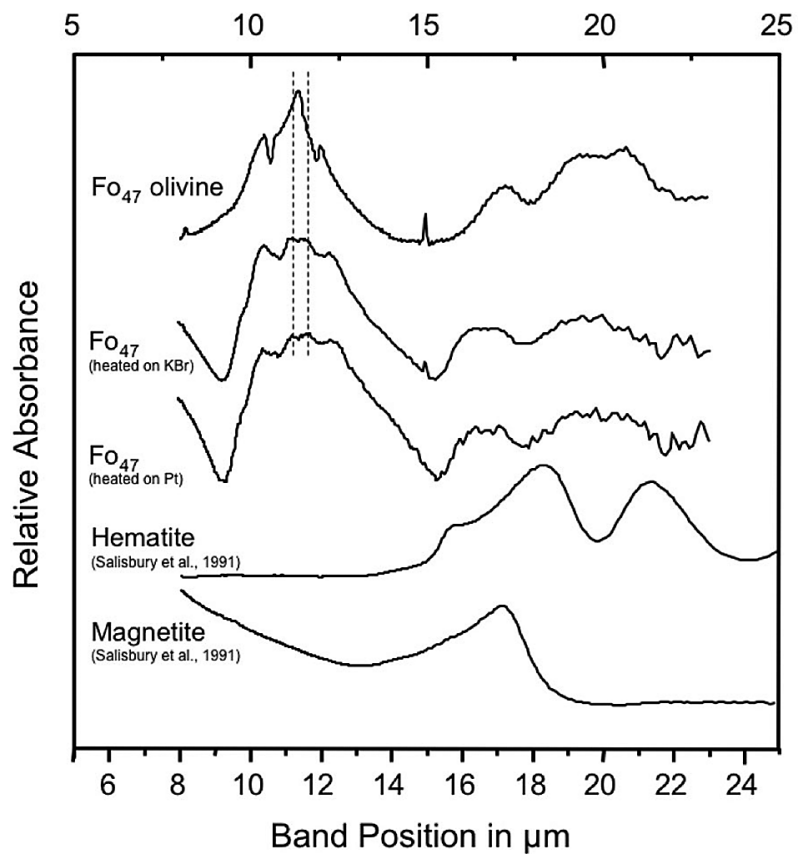

Figure 4. Mid-infrared spectra of cooled $\mathrm{Fo}_{47}$ olivines after heating at $600{ }^{\circ} \mathrm{C}$ in air on a $\mathrm{KBr}$ pellet (average of 5 spectra) and a platinum foil (average of 7 spectra), $\mathrm{Fo}_{47}$ olivines before heating, hematite $\left(\mathrm{Fe}_{2} \mathrm{O}_{3}\right)$, and magnetite $\left(\mathrm{Fe}_{3} \mathrm{O}_{4}\right)$. Data of iron oxides are from Salisbury et al. (1992). 


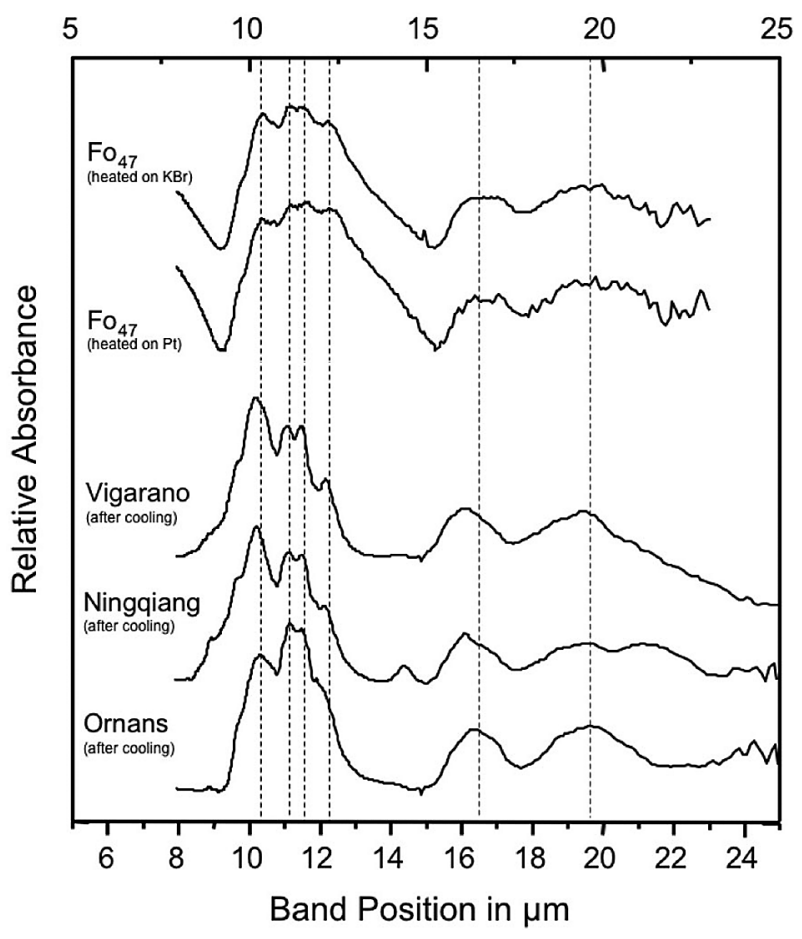

Figure 5. Mid-infrared spectra of heated $\mathrm{Fo}_{47}$ olivine and the matrices of carbonaceous chondrites. The positions of major olivine bands are shown as dotted lines.

$\mathrm{nm}$ spacing, corresponding three-fold length of the olivine $c$-axis, could be recognized because of the high stacking disorder on the (001) plane (Fig. 8d).

\section{DISCUSSION}

The three-fold superstructure of Fe-bearing olivine observed by TEM in the present study was previously reported in natural and synthetic oxidized fayalite, known as laihunite, which was first discovered in terrestrial rocks (Kitamura et al., 1984; Kondoh et al., 1985; Shen et al., 1986). Laihunite has an olivine structure with a composition of $v_{\mathrm{x}} \mathrm{Fe}_{2-3 \mathrm{x}}^{2+} \mathrm{Fe}_{2 \mathrm{x}}^{3+} \mathrm{SiO}_{4}$, where $v$ is the vacancy (Kitamura et al., 1984; Shen et al., 1986). It has a monoclinic unit cell of $a=0.481 \mathrm{~nm}, b=1.019 \mathrm{~nm}, c=0.580 \mathrm{~nm}$, and $\alpha=$ $91.0^{\circ}$ in the $\mathrm{Fe}_{2} \mathrm{SiO}_{4}$ composition (Tamada et al., 1983). However, natural and synthetic laihunites often have superlattices with two-fold ( $2 M$ structure) and three-fold ( $3 M$ structure) periodicities along the $c$ axis of fayalite, owing to the ordering of the cation and vacancy sites (Kondoh et al., 1985; Kitamura et al. 1984; Shen et al., 1986). The laihunite identified by TEM in the present study corresponded to the $3 M$ superstructure. The $3 M$ phase was also found in more $\mathrm{Mg}$-rich olivine $\left(\mathrm{Fo}_{89}\right)$ experimentally heated at $600{ }^{\circ} \mathrm{C}$ and $700{ }^{\circ} \mathrm{C}$ and high $f_{\mathrm{O}_{2}}(0.2$ atm) conditions (Khisina et al., 1995).

Concerning mass balance, the oxidation of Fe-bear-

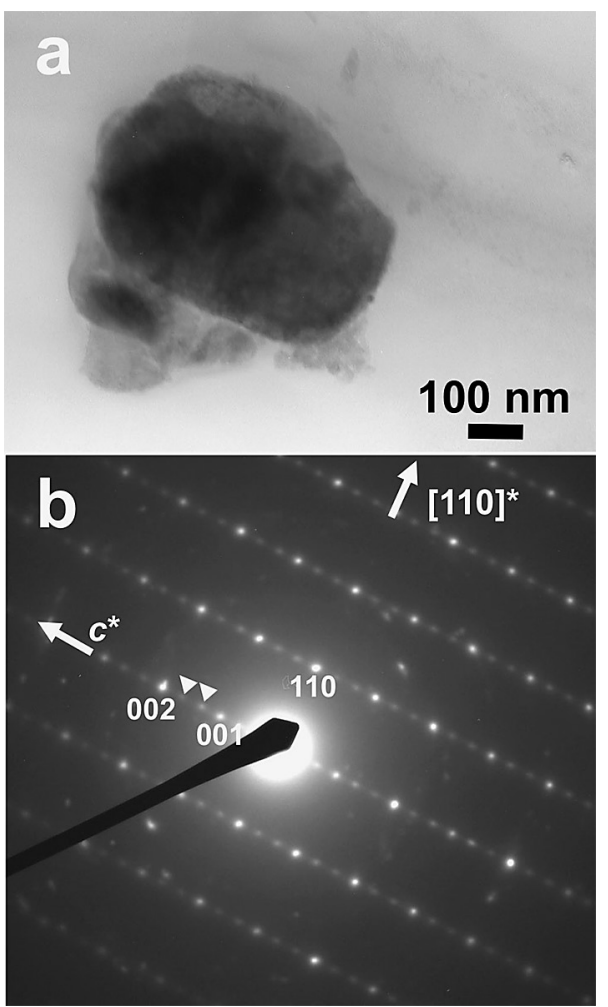

Figure 6. A matrix olivine grain from a heated Vigarano chondrite. (a) Transmission electron micrograph. (b) Selected area electron diffraction (SAED) pattern. Super-lattice reflections corresponding to three-fold periodicity along the $c$ axis of olivine are present.

ing $\left(\mathrm{Fo}_{47}\right)$ olivine observed in this study can be expressed as the following equation:

$$
\begin{aligned}
& \mathrm{Mg}_{0.94} \mathrm{Fe}_{1.06} \mathrm{SiO}_{4} \text { (olivine) }+2 x / 3 \mathrm{O}_{2} \Rightarrow \\
& \mathrm{Mg}_{0.94} \mathrm{Fe}_{x} \mathrm{Fe}_{(1.06-3 x)}^{2+} \mathrm{Fe}_{2 x}^{3+} \mathrm{SiO}_{4} \text { (laihunite) } \\
& \quad+x / 3 \mathrm{Fe}_{3} \mathrm{O}_{4} \text { (magnetite) }
\end{aligned}
$$

In this reaction, the amount of magnetite is much less than that of laihunite. This is consistent with our results, since magnetite was not observed much under TEM or in the FTIR spectra (Figs. 4 and 5). Laihunite- $2 M$ was not found in either synthetic or meteoritic olivines in our TEM observations. Previous oxidation experiments of fayalite at $400-700{ }^{\circ} \mathrm{C}$ for $5-480 \mathrm{~h}$ clarified that fayalite initially transforms to the $3 M$ structure, and further oxidation produces the $2 M$ structure (Kondoh et al., 1985). The relatively short heating duration in the present study $(<3 \mathrm{~h})$ may have prevented progression of the oxidation of olivine to form the $2 \mathrm{M}$ phase.

The following effects can be considered when investigating causes of changes in mid-infrared spectra in chondrite matrices during heating: (1) Fe-oxide formation by oxidation breakdown of Fe-rich olivine, (2) reactions 

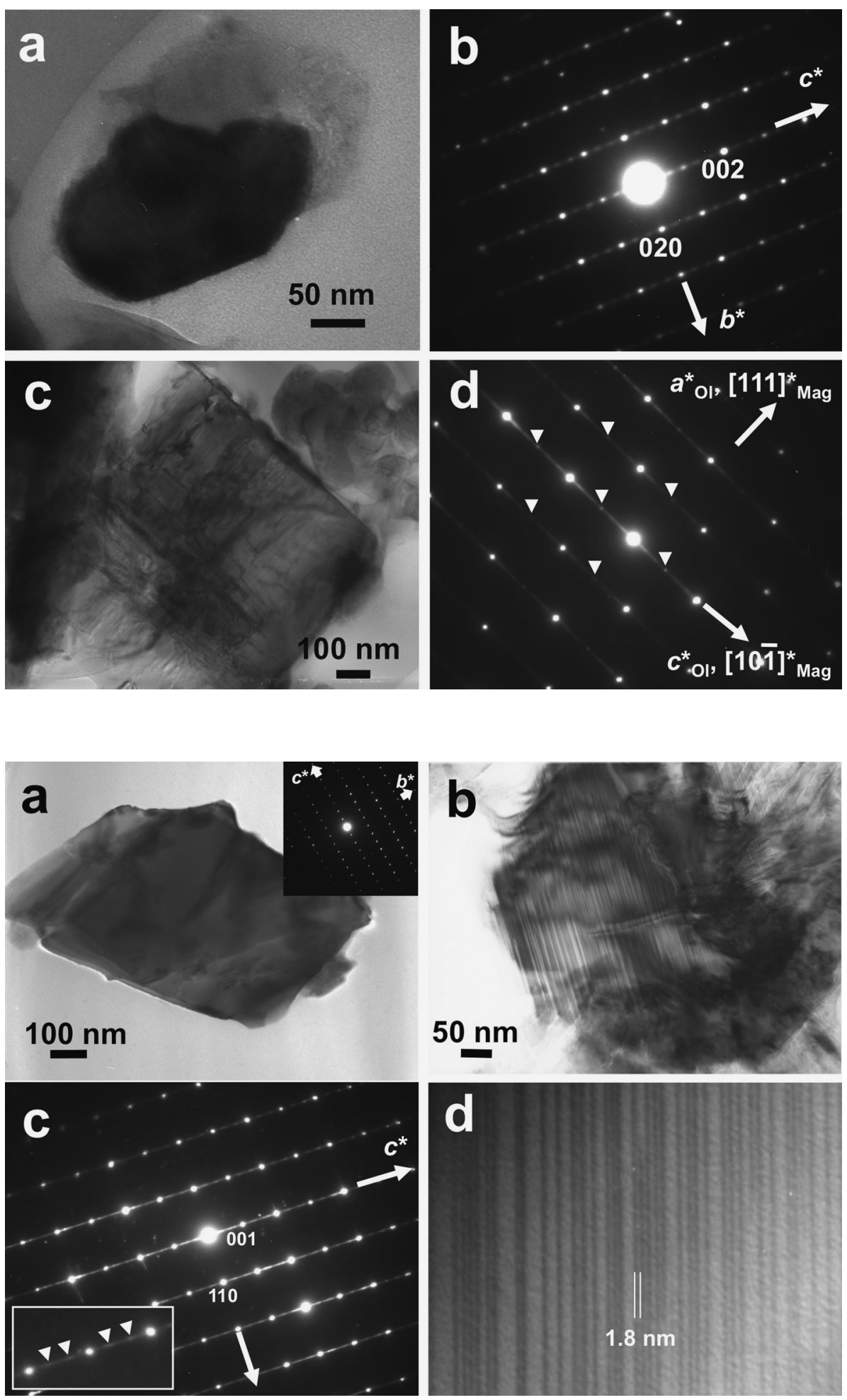

Figure 7. Olivine grains in the matrix of a heated Ningqiang chondrite after cooling. (a) Transmission electron micrograph of an olivine grain with stacking disorder on the (001) plane. (b) SAED pattern taken from the grain in (a) shows weak reflections along the $c^{*}$ direction corresponding to those of laihunite- $3 M$. (c) Transmission electron micrograph of an olivine grain containing magnetite. (d) SAED pattern taken from the grain in (c). Diffuse scattering are shown along the $c^{*}$ direction of olivine $(\mathrm{Ol})$. Weaker diffraction spots indicated by triangles correspond to those of magnetite (Mag).

Figure 8. Synthetic olivine grains with $\mathrm{Fo}_{47}$ composition. (a) Electron micrograph of unheated olivine. The olivine grain does not have any stacking disorder. SAED pattern of the olivine grain is in the inset. (b) Transmission electron micrograph of olivine heated at $600{ }^{\circ} \mathrm{C}$ showing stacking disorder. (c) SAED pattern taken from the grain in (b). (Inset) Superlattice reflections of three-fold periodicity along the $c$ axis of olivine. (d) High-resolution electron micrograph of heated olivine showing $1.8 \mathrm{~nm}$ spacing of the laihunite- $3 M$ structure. among constituent minerals of the chondrite matrices, and (3) chemical reactions between matrix minerals and $\mathrm{KBr}$ pellets.

As for (1), ferric-iron bearing minerals such as hematite and magnetite did not exhibit their characteristic bands in the wavelength range of $\sim 10-12 \mu \mathrm{m}$ in the FTIR spectra (Fig. 4). This suggests that the mid-infrared spectra in this range were not affected by the Fe-oxides, even if those produced by heating are in a high amount. As for (2), the Vigarano, Ningqiang, and Ornans chondrites consisted mainly of Fe-rich olivine and lesser amounts of pyroxene, Fe-metal, Fe-sulfide, and Fe-oxide (Rubin et al., 
1988; Buseck and Hua, 1993; Lee et al., 1996). However, both chondritic matrices and synthetic olivine samples showed similar spectral changes in major bands for olivine in the range of $\sim 10-12 \mu \mathrm{m}$. As for (3), there was no obvious difference in the FTIR spectra of Fe-rich olivine between the sample heated on a $\mathrm{KBr}$ pellet and on a platinum foil. Therefore, a chemical reaction with a $\mathrm{KBr}$ pellet can be ruled out as a cause of spectral change by heating. The major spectral changes would have been caused by structural modification of olivine, as speculated in the above oxidation reaction, rather than by effects of other mineral constituents before and after heating. The mid-infrared spectra of the oxidized olivines in the present study were similar to that of natural laihunite (ferrifayalite) in terrestrial rocks (Huggins, 1970: Zhang et al., 1981; Schaefer, 1985), with a relatively high intensity of the 10$\mu \mathrm{m}$ band with respect to the intensity of the- $11 \mu \mathrm{m}$ band; however, natural laihunite does not exhibit the split of the $11-\mu \mathrm{m}$ band, which was observed in this study.

The band positions of olivine increased to longer wavelengths with increasing fayalite content (Koike et al., 2003; Morlok et al., 2006). The $\mathrm{Mg} / \mathrm{Fe}$ ratio in oxidized olivine (laihunite) is higher than non-oxidized olivine in the oxidation reaction mentioned above. If the splitting of the $\sim 11-\mu \mathrm{m}$ band was caused by dissociation to non-oxidized olivine and oxidized olivine with different $\mathrm{Mg} / \mathrm{Fe}$ ratios, the $\sim 10-\mu \mathrm{m}$ and $12-\mu \mathrm{m}$ bands should also have split, because these band shifts are also sensitive to fayalite content (Koike et al. 2003; Morlok et al. 2006). However, splitting of the $\sim 10-\mu \mathrm{m}$ and $\sim 12-\mu \mathrm{m}$ bands was not observed in the samples in the present study. Therefore, the splitting of the $\sim 11-\mu \mathrm{m}$ band was not simply caused by the $\mathrm{Mg} / \mathrm{Fe}$ ratio in olivine, but by the formation of a slightly different vibration mode of $\mathrm{Si}-\mathrm{O}$ in the laihunite structure from those of non-oxidized olivine at the $\sim 11-\mu \mathrm{m}$ region. Ferric iron sites and/or vacancy sites in the laihunite structure could locally change the frequency of the Si-O stretching vibration. The degree of splitting of the $11-\mu \mathrm{m}$ band and the intensity ratio of the $10-\mu \mathrm{m}$ and $11-\mu \mathrm{m}$ bands could explain relative abundances of oxidized and non-oxidized domains in the samples.

As mentioned above, in the samples of Ornans (CO3) and synthetic olivines after cooling, the splitting of the $11-\mu \mathrm{m}$ band and the increase in the intensity of the $10-\mu \mathrm{m}$ band relative to that of the $11-\mu \mathrm{m}$ band were less significant than the Vigarano and Ningqiang (CV3) samples, despite identical heating duration $(\sim 3 \mathrm{~h})$. In general, $\mathrm{CV} 3$ and $\mathrm{CO} 3$ chondrites are nominally anhydrous, but contain up to $\sim 4.5 \mathrm{wt} \%$ of water (Jarosewich, 1990), mostly as structural water in minerals such as phyllosilicates found in chondrule rims in the Vigarano CV3 chon- drite (Tomeoka and Tanimura, 2000). It was experimentally clarified that Fe-rich olivine is oxidized to form laihunite in alkaline aqueous solutions at $300{ }^{\circ} \mathrm{C}$ and 100 bar (Iishi et al., 1997). The spectral differences among the samples may have been caused by different degrees of oxidation of Fe-rich olivine, depending on the amount of water in each sample. In particular, the synthetic olivine contained only trace amounts of water, if at all. In which case, the above changes in the FTIR spectra of the synthetic olivine would be the least significant among the samples, although more quantitative studies of water effects on the oxidation process are necessary.

The present study found that oxidation of Fe-rich olivine in complex mineral assemblages, such as chondritic materials including pyroxene, Fe-metal, Fe-sulfide among others, could be recognized by the effects on the $\mathrm{Si}-\mathrm{O}$ vibration modes in mid-infrared spectroscopy. The changes in mid-infrared spectra of olivine-dominating samples are potential reference data for oxidation state of olivine in planetary materials.

Detailed infrared laboratory studies on the formation of environmentally sensitive phases like laihunite are necessary for better interpretation of laboratory analyses of planetary samples. Successful sample return missions, e.g., STARDUST (Keller et al., 2006) and recently HAYABUSA (Kitajima et al., 2011), all included micro-FTIR studies as one of the first steps for the analysis of the precious and fine-grained returned materials, since they allow the non-destructive study of these rare and unique samples. A detailed database including indicator phases, especially for environmental conditions, is crucial for the interpretation of these results. This is also of special interest regarding the upcoming/planned sample return missions NASA OSIRIS-Rex, JAXA HAYABUSA-2 (Kawaguchi et al., 2008), and ESA MarcoPolo-R (Barucci et al., 2012) of carbonaceous chondrite type near-Earth asteroids, where the identification of any hydrous or oxidized phases will be crucial for the understanding of the degree of alteration of these bodies (Lauretta et al., 2012). The results from this study also provide new data to investigate alteration in related IDPs, which are also analyzed using micro-FTIR studies (Brunetto et al., 2011).

Furthermore, these results have potential application for astronomical infrared studies of dust in comets or in young, forming solar systems (e.g., debris disks), where dust from oxidized planetesimals and asteroids are observed (Currie et al., 2011; Lisse 2009; Morlok et al., 2010). That is, FTIR analyses have the potential to link and apply laboratory studies of planetary materials with astronomical observations.

Finally, these results are also of interest for planetary lander/rover missions. FTIR is a potential instrument for 
future in situ measurements on the Martian surface, as it is one of fundamental instruments in cosmochemistry, which allows analyses of both mineral and organic compounds. Previously, a Mössbauer spectrometer equipped on the Mars rover Opportunity successfully detected jarosite $\left[(\mathrm{K}, \mathrm{Na})(\mathrm{Fe}, \mathrm{Al})_{3}\left(\mathrm{SO}_{4}\right)_{2}(\mathrm{OH})_{6}\right]$ and hematite-containing ferric iron, suggesting high $-f_{\mathrm{H}_{2} \mathrm{O}}$ and high $-f_{\mathrm{O}_{2}}$ conditions on Mars (Klingelhöfer et al., 2004). FTIR provides the entire range of structural information on not only Febearing minerals but also Fe-free ones. Therefore, it has an advantage to obtain comprehensive data sets on mineralogy and biochemistry of Martian rocks (Anderson et al., 2005).

\section{ACKNOWLEDGMENTS}

TEM analyses were performed at the Instrumentation Analysis Division, Kobe University. We thank Tomoo Katsura for providing the synthetic olivine sample and Ichiro Ohnishi and Kaushik Das for their comments. This paper has benefited from careful reviews by Takaaki Noguchi and Masaaki Miyahara. This work was partly supported by The 21st Century COE program of Origin and Evolution of Planetary Systems of the Ministry of Education, Science, Culture, Sports, and Technology.

\section{REFERENCES}

Anderson, M.S., Andringa, J.M., Carlson, R.W., Conrad, P., Hartford, W., Shafer, M., Soto, A., Tsapin, A.I., Dybwad, J.P., Wadsworth, W. and Hand, K. (2005) Fourier transform infrared spectroscopy for Mars science. Review of Scientific Instruments, 76, 034101.

Banfield, J.F., Dyar, M.D. and McGuire, A.V. (1992) The defect microstructure of oxidized mantle olivine from Dish Hill, California. American Mineralogist, 77, 977-986.

Barucci, M.A., Cheng, A.F., Michel, P., Berner, L.A.M., Binzel, R.P., Bland, P.A., Böhnhardt, H., Brucato, J.R., Campo Bagatin, A., Cerroni, P., Dotto, E., Fitzsimmons, A., Franchi, I.A., Green, S.F., Lara, L.-M., Licandro, J., Marty, B., Muinonen, K., Nathues, A., Oberst, J., Rivkin, A.S., Robert, F., Saladino, R., Trigo-Rodriguez, J.M., Ulamec, S. and Zolensky, M. (2012) MarcoPolo-R: Near earth asteroid sample return mission. Experimental Astronomy 33, 645-684.

Bläß, U.W., Langenhorst, F. and McCammon, C. (2010) Microstructural investigations on strongly stained olivines of the chassignite NWA 2737 and implications for its shock history. Earth and Planetary Science Letters, 300, 255-263.

Brearley, A.J. and Jones R.H. (1998) Chondritic meteorites. In Planetary Materials (Papike, J.J. Ed.). Mineralogical Society of America, Washington D.C., 1-398.

Brearley, A.J. (2003) Nebular versus parent-body processing. In Treatise on Geochemistry, Meteorites, Comets and Planets (Davis, A.M. Ed.). pp. 737, Elsevier, Oxford. 247-268.

Brunetto, R., Borg, J., Dartois, E., Rietmeijer, F.J.M., Grossemy, F., Sandt, C., Le Sergeant D'Hendecourt, L., Rotundi, A., Dumas, P., Djouadi, Z. and Jamme, F. (2011) Mid-IR, far-IR,
Raman micro-spectroscopy, and FESEM-EDX study of IDP L2021C5: Clues to its origin. Icarus, 212, 896-910.

Buseck, P.R. and Hua, X. (1993) Matrices of carbonaceous chondrite meteorites. Annual Review of Earth and Planetary Sciences, 21, 255-305.

Chihara, H., Koike, C., Tsuchiyama, A., Tachibana, S. and Sakamoto, D. (2002) Compositional dependence of infrared absorption spectra of crystalline silicates I. Mg-Fe pyroxenes. Astronomy \& Astrophysics, 391, 267-273.

Currie, T., Lisse, C.M., Sicilia-Aguilar, A., Rieke, G.H. and Su, K.Y.L. (2011) Spitzer IRS spectroscopy of the $10 \mathrm{Myr}-$ old EF Cha debris disk: Evidence for phyllosilicate-rich dust in the terrestrial zone. The Astrophysical Journal, 734, doi: 10.1088/0004-637X/734/2/115.

Ehlman, B.L., Mustard, J.F., Murchie, S.L., Bibring, J.-P., Meunier, A., Fraeman, A.A., Langevin, Y. (2011) Subsurface water and clay mineral formation during the early history of Mars. Nature, 479, 53-60.

Fegley, B., Treiman, A.H. and Sharpton, V.L. (1992) Venus surface mineralogy: Observational and theoretical constraints. Proceedings of Lunar and Planetary Science, 22, 3-19.

Greshake, A., Klöck, W., Arndt, P., Maetz, M. and Bischoff, A. (1994) Pulse heating of fragments from Orgueil (CI): Simulation of atmospheric entry heating of mircometeorites. Meteoritics, 29, 470.

Guofei, F. and Rietmeijer, F.J.M. (1994) Ferrosilite, fayalite and magnesioferrite formation by isothermal annealing of an iron-contaminated $\mathrm{Mg}-\mathrm{SiO}$ smoke (abstact). 25th Lunar and Planetary Science Conference, 493-494.

Hofmeister, A.M. (1987) Single-crystal absorption and reflection infrared spectroscopy of forsterite and fayalite. Physics and Chemistry of Minerals, 14, 499-513.

Huggins, F.E. (1970) Infra-red study of some orthosilicate minerals. B.A. thesis, pp.136, Oxford University, Oxford.

Iishi, K., Torigoe, K. and Han, X.J. (1997) Oriented precipitate complexes in iron-rich olivines produced experimentally in aqueous oxidizing environment. Physics and Chemistry of Minerals, 25, 8-14.

Jarosewich, E. (1990) Chemical analyses of meteorites: A compilation of stony and iron meteorite analyses. Meteoritics, 25, 323-337.

Kawaguchi, J., Fujiwara, A. and Uesugi, T. (2008) Hayabusa-Its technology and science accomplishment summary and Hayabusa-2, Acta Astronautica, 62, 639-647.

Keller, L.P., Thomas, K.L. and McKay, D.S. (1992) Thermal processing of cosmic dust: Atmospheric heating and parent body metamorphism. LPSC, XXIII, 675-676.

Keller, L.P., Thomas, K.L. and McKay, D.S. (1996) Mineralogical changes in IDPs resulting from atmospheric entry heating. ASP Conference Series, 104, 295-298.

Keller, L.P., Bajt, S., Baratta, G. A., Borg, J., Bradley, J.P., Brownlee, D.E., Busemann, H., Brucato, J.R., Burchell, M., Colangeli, L., d'Hendecourt, L., Djouadi, Z., Ferrini, G., Flynn, G., Franchi, I.A., Fries, M., Grady, M.M., Graham, G.A., Grossemy, F., Kearsley, A., Matrajt, G., Nakamura-Messenger, K., Mennella, V., Nittler, L., Palumbo, M.E., Stadermann, F.J., Tsou, P., Rotundi, A., Sandford, S.A., Snead, C., Steele, A., Wooden, D. and Zolensky, M. (2006) Infrared spectroscopy of comet $81 \mathrm{P} /$ Wild 2 samples returned by Stardust. Science, 314, 1728-1731.

Khisina, N.R., Khramov, D.A., Kolosov, M.V., Kleschev, A.A. and Taylor, L.A. (1995) Formation of ferriolivine and magnesio- 
ferrite from $\mathrm{Mg}-\mathrm{Fe}$-olivine: Reactions and kinetics of oxidation. Physics and Chemistry of Minerals, 22, 241-250.

Kitajima, F., Kotsugi, M., Ohkochi, T., Naraoka, H., Ishibashi, Y., Abe, M., Fujimura, A., Okazaki, R., Yada, T., Nakamura, T., Noguchi, T., Nagao, K., Tsuchiyama, A., Mukai, T., Sandford, S.A., Okada, T., Shirai, K., Ueno, M., Yoshikawa, M. and Kawaguchi, J. (2011) A micro-spectroscopic approach to the carbonaceous matter in the particles recovered by the Hayabusa mission (abstract). 42nd Lunar and Planetary Science Conference, 1855.pdf.

Kitamura, M., Shen, B., Banno, S. and Morimoto, N. (1984) Fine textures of laihunite, a nonstoichiometric distorted olivinetype mineral. American Mineralogist, 69, 154-160.

Klingelhöfer, G., Morris, R.V., Bernhardt, B., Schröder, C., Rodionov, D.S., de Souza Jr., P.A., Yen, A., Gellert, R., Evlanov, E.N., Zubkov, B., Foh, J., Bonnes, U., Kankeleit, E., Gütlich, P., Ming, D.W., Renz, F., Wdowiak, T., Squyres, S.W. and Arvidson R.E. (2004) Jarosite and hematite at Meridiani Planum from Opportunity's Mössbauer spectrometer. Science, 306, 1740-1745.

Koike, C., Chihara, H., Tsuchiyama, A., Suto, H., Sogawa, H. and Okuda, H. (2003) Compositional dependence of infrared absorption spectra of crystalline silicate. II. Natural and synthetic olivines. Astronomy \& Astrophysics, 399, 1101-1107.

Kondoh, S., Kitamura, M. and Morimoto, N. (1985) Synthetic laihunite $\left(\square_{x} \mathrm{Fe}_{2-3 \mathrm{x}}^{2+} \mathrm{Fe}_{2 \mathrm{x}}^{3+} \mathrm{SiO}_{4}\right)$, an oxidation product of olivine. American Mineralogist, 70, 737-746.

Lauretta, D.S. and OSIRIS-Rex team (2012) An overview of the OSIRIS-REx asteroid sample return mission (abstract). 43rd Lunar and Planetary Science Conference, 2491.pdf.

Lee, M.R., Hutchison, R. and Graham, A.L. (1996) Aqueous alteration in the matrix of the Vigarano (CV3) carbonaceous chondrite. Meteoritics \& Planetary Science, 31, 477-483.

Lisse, C.M. (2009) Laboratory astronomy needs for the study of dust in comets in the next decade. Bulletin of the American Astronomical Society, 41, 744.

Morlok, A., Bowey, J., Köhler, M. and Grady, M.M. (2006) FTIR 2-16 micron spectroscopy of micron-sized olivines from primitive meteorites. Meteoritics \& Planetary Science, 41, 773-784.

Morlok, A., Koike, C., Tomioka, N., Mann, I. and Tomeoka, K. (2010) Mid-infrared spectra of the shocked Murchison CM chondrite: Comparison with astronomical observations of dust in debris disks. Icarus, 207, 45-53.

Noguchi, T., Nakamura, T., Misawa, K., Imae, N., Aoki, T. and Toh, S. (2009) Laihunite and jarosite in the Yamato 00 nakhlites: Alteration products on Mars? Journal of Geophysical Research, 114, doi:10.1029/2009JE003364.

Nozaki, W., Nakamura, T. and Noguchi, T. (2006) Bulk mineralogical changes of hydrous micrometeorites during heating in the upper atmosphere at temperatures below $1000{ }^{\circ} \mathrm{C}$. Meteoritics \& Planetary Sciences, 41, 1095-1114.
Ostertag, R., Amthauer, G., Rager, H. and McSween, H.Y. (1984) $\mathrm{Fe}^{3+}$ in shocked olivine crystals of the ALHA 77005 meteorite. Earth and Planetary Science Letters, 67, 162-166.

Rietmeijer, F.J.M. (1993) Atmospheric entry heating: Evidence for texturally heterogeneous comet nuclei? Meteoritics, 28, 422.

Rost, D., Vicenzi, E.P. and Fries, M. (2006) A host for lithium in MIL03346 and implications for aqueous alteration on Mars (abstract). Lunar and Planetary Science XXXVII, 2362.pdf.

Rubin, A.E., Wang D., Kallemeyn, G.W. and Wasson J.T. (1988) The Ningqiang meteorite: Classification and Petrology of an Anomalous CV Chondrite. Meteoritics, 23, 13-23.

Salisbury, J.W., Walter, L.S., Vergo, N. and D'Aria, D.M. (1992) Infrared (2.1-25 $\mu \mathrm{m})$ spectra of minerals. pp. 296, Maryland: Johns Hopkins University Press, Maryland.

Schaefer, M.W. (1985) Site occupancy and two-phase character of 'ferrifayalite'. American Mineralogist, 70, 729-736.

Shen, B., Tamada, O., Kitamura, M. and Morimoto, N. (1986) Superstructure of laihunite- $3 M\left(\square_{0.40} \mathrm{Fe}_{0.80}^{2+} \mathrm{Fe}_{0.80}^{3+} \mathrm{SiO}_{4}\right)$. American Mineralogist, 71, 1455-1460.

Tamada, O., Shen, B. and Morimoto, N. (1983) The crystal structure of laihunite $\left(\square_{0.40} \mathrm{Fe}_{0.80}^{2+} \mathrm{Fe}_{0.80}^{3+} \mathrm{SiO}_{4}\right)$ - nonstoichiometric olivine-type mineral. Mineralogical Journal, 11, 382-391.

Tomeoka, K. and Buseck, P. (1990) Phyllosilicates in the Mokoia $\mathrm{CV}$ carbonaceous chondrite: Evidence for aqueous alteration in an oxidizing environment. Geochimica et Cosmochimica Acta, 54, 1745-1754.

Tomeoka, K. and Tanimura, I. (2000) Phyllosilicates-rich chondrule rims in the Vigarano CV3 chondrite: Evidence for parent-body processes. Geochimica et Cosmoshimica Acta, 64, 1971-1988.

Wiseman, S.M., Arvidson, R.E., Morris, R.V., Poulet, F., Andrews-Hanna, J.C., Bishop, J.L., Murchie, S.L., Seelos, F.P., Des Marais, D. and Griffes, J.L. (2010) Spectral and stratigraphic mapping of hydrate sulfate and phyllosilicate-bearing deposits in northern Sinus Meridiani, Mars. Journal of Geophysical Research, 115, doi: 10.1029/2009JE003354.

Zhang, R., Cong, B, Ying, Y. and Li, J. (1981) Ferrifayalite-bearing eulysite from Archaean granulites in Qianan county, Hebei, North China. Tschermaks Mineralogische und Petrographische Mitteilungen, 28, 167-187.

Zolensky, M., Nakamura, K., Weisberg, M.K., Printz, M., Nakamura, T., Ohsumi, K., Saitow, A., Mukai, M. and Gounelle, M. (2003) A primitive dark inclusion with radiation-damaged silicates in the Ningqiang carbonaceous chondrite. Meteoritics \& Planetary Sciences, 38, 305-322.

Manuscript received April 9, 2012

Manuscript accepted July 12, 2012

Manuscript handled by Takashi Mikouchi 